\title{
Risk of eating disorders in a representative sample of Italian adolescents: prevalence and association with self-reported interpersonal factors
}

\author{
Giulio D'Anna ${ }^{1}$ Marco Lazzeretti ${ }^{2}$. Giovanni Castellini ${ }^{1}$ (1) - Valdo Ricca ${ }^{1}$ Emanuele Cassioli ${ }^{1}$ Eleonora Rossi ${ }^{1}$. \\ Caterina Silvestri' ${ }^{2} \cdot$ Fabio Voller $^{2}$
}

Received: 15 March 2021 / Accepted: 11 May 2021 / Published online: 20 May 2021

(c) The Author(s) 2021

\begin{abstract}
Purpose Adolescence represents a critical period for the onset of eating disorders (EDs). The present study aimed to provide the prevalence of individuals at risk for EDs psychopathology in a representative population of adolescents aged 14-19 and to characterize this population regarding interpersonal and psychological factors.

Methods The percentage of participants at risk for EDs in a representative high school population was assessed through the SCOFF screening questionnaire (cut-off score: 3 ) in the total sample (N: 6551) and in gender-based subgroups for different body mass index (BMI) categories. Odds ratios for being at risk of $\mathrm{ED}(\mathrm{SCOFF} \geq 3$ ) were esteemed in a multivariable analysis including self-reported parental education, quality of family and peer relationships, bullying victimization, age at first sexual intercourse, and psychological distress.

Results A SCOFF score $\geq 3$ was found in $31.0 \%$ of participants (boys: $19.4 \%$; girls: $44.6 \%$ ), with a greater prevalence among higher BMI categories. Bad family relationships, being bullied, having the first sexual intercourse before the age of 14 , and experiencing high distress were associated with this risk condition. Among girls, bad peer relationships were associated with a low-risk SCOFF score.

Conclusion A remarkable percentage of adolescents reported significant body image or eating concerns. Screening programs are deeply needed, and particular attention should be devoted to interpersonal factors, such as the quality of family relationships and interactions with peers, which represent potential indicators of this vulnerability.

Level of evidence Level V - Cross-sectional study.
\end{abstract}

Keywords Adolescence $\cdot \mathrm{SCOFF} \cdot$ Family relationships $\cdot$ Bullying victimization $\cdot$ Sexuality $\cdot$ Psychological distress

\section{Introduction}

Recent studies seem to demonstrate an increased incidence of cases of eating disorders (EDs) among adolescents in the last decades [1]. However, a precise estimate of the prevalence of subthreshold and clinical conditions in this high-risk age interval is still under-addressed in European countries [2], and data from previous Italian studies may

Giovanni Castellini

giovanni.castellini@unifi.it

1 Psychiatry Unit, Department of Health Sciences, University of Florence, Azienda Ospedaliero-Universitaria Careggi,

Largo Brambilla 3, 50134 Florence, Italy

2 Agenzia Regionale Di Sanità Della Toscana, Florence, Italy benefit from an update [3-6]. In fact, early detection of ED psychopathology is fundamental for a timely treatment and a reduction of chronicity [7]. For this reason, an accurate characterization of at-risk conditions-including different environmental, interpersonal, and psychological factors clustering with them - may contribute to a more precise estimation of the number of subclinical conditions or untreated subjects with EDs [2, 8].

On the one hand, the presence of shared risk factors between disordered eating and a condition of overweight among adolescents has been clearly outlined [9], and a history of overweight or obesity is potentially associated with the development of EDs [10], including dietary restraint and subsequent weight loss [11].

When exploring this framework, perceived social norms and family environment have shown to influence both eating 
behavior and body image concerns [12], and - since a cultural influence in EDs is clearly established [13]—-socioeconomic determinants are probably involved in a complex and multifaceted manner. In this sense, parental education level has shown a clear gender- and-disorder-specific predictive value in a large naturalistic cohort, differently from indicators such as income or social class [14].

Regarding interpersonal and psychological factors, the development of ED symptoms may be related to difficulties in family interactions [15-17]- possibly involving the widely described role of dysfunctional attachment patterns [18] — but also to psychological distress [19], and relationships with peers [17, 20, 21]. More in details, the latter were found to influence weight-related behavior [20], and bullying victimization was associated with weight and body image concerns among adolescents [21]. In fact, premorbid social difficulties in EDs include submissiveness and proneness to dysfunctional social comparison [22]. Moreover, experiencing family and peer teasing in early adolescence is associated with the development of dysfunctional weight control tied to body image dissatisfaction [17]. To conclude, the quality of early sexual experiences has already been reported to be interconnected with EDs psychopathology [23, 24], early sexual activity being associated with bulimic-type pathology in middle adolescence [25]. Considering that ED patients are known to show abnormal emotional reactivity associated with body dissatisfaction in presence of social stressors [26], an early assessment of the abovementioned relational factors may enrich the epidemiological data available, coherently with the interpersonal model of EDs.

The present study aimed to produce the first evaluation of the prevalence of EDs symptoms in a representative population of Italian adolescents, and to explore differences in risk for ED psychopathology across known risk factors related to family environment, peer relationships, psychological distress, and body weight.

\section{Methods}

The present investigation is part of the larger EDIT (Epidemiologia dei Determinanti dell'Infortunistica stradale Toscana) study on at-risk behavior among Italian adolescents.

In 2018, Agenzia Regionale di Sanità (ARS) Toscana collected data from 6824 individuals aged 14-19 years who were attending 85 public high schools of Tuscany (Italy). To avoid an inadequate representation of age, gender, type of school attended, and geographic region, institutions were selected through a randomization process based on sociodemographic data provided by the Regional Board of Studies. For each school, five classes were randomly chosen from different sections to avoid biases related to specific characteristics of each section.
The survey procedure was explained before inclusion in the study, and written informed consent was collected from participants, and from their parents or legal guardians (for individuals younger than 18 years). Enrolled subjects answered a self-reported questionnaire on an electronic form during school hours, and confidentiality was always ensured. The study protocol was approved by the Ethics Committee of the organizing institution.

\section{Measurements and variables}

Enrolled individuals reported their age, gender, height, and weight. Body mass index (BMI) was obtained from selfreported weight and height. BMI normative percentiles outlined four categories within the total sample [27, 28]: "Underweight" (BMI < 5th percentile), "Normal weight" (5th-85th percentile), "Overweight" (85-95th percentile), and "Obesity" ( $>95$ th percentile).

Participants were asked to fill the Italian version of the SCOFF questionnaire, a 5-item survey with dichotomous answers ("Yes": 1 point; "No": 0 points) for the screening of EDs [29, 30]. Questions refer to the acronym SCOFF and investigate feelings of sickness related to being uncomfortably full (Sick), perceived loss of control when eating (Control), a recent loss of at least six kilograms in a three-month period (One stone), perceiving oneself as fat (Fat), and the idea that food is dominating the respondent's life (Food). Individual scores range from 0 to 5 , with higher scores indicating a higher number of ED symptoms. The cut-off score for risk of an ED in the Italian version is 3, with a sensitivity of $97.0 \%$, and a specificity of $87.5 \%$ in detecting EDs [30].

Family environment was evaluated through self-reported highest parental education level ("Graduated" or "Not graduated" from university), and through the perceived quality of family relationships, categorized as "Good" (if "Very good" or "Quite good"), "Intermediate" (if self-reported as "So and so"), or "Bad" (if "Not very good" or "Not good at all").

Peer relationships were investigated through a selfreported questionnaire and categorized as described for family relationships. In addition, the survey asked whether participants had been physically or verbally bullied by peers, including cyberbullying, during the previous year ("Yes" or "No"), and the age at the time of the first complete sexual intercourse (pragmatically categorized as $<14$ years or $\geq 14$ years, which is the usual age at the beginning of high school, and, therefore, the minimum age in the analyzed sample).

Perceived psychological distress was evaluated through the K6 scale [31]. This screening scale contains six Likertformat items which assess feelings of hopelessness, depression, uselessness, nervousness, restlessness, and feeling overwhelmed in the past 30 days (from 1, "Never", to 5, "Always"). Scores $>18$ were classified as "High distress". 
The K6 scale proved to have adequate psychometric properties in an adolescent population [32].

\section{Data analysis}

Participants were excluded from analysis if they had not answered the SCOFF questionnaire. After excluding individuals who did not provide consent or did not answer the SCOFF questionnaire, the sample was checked for selective participation, to confirm that it did not significantly differ from the initial one regarding randomization criteria (age, gender, geographic region of origin, and type of school attended). Descriptive statistics — divided by gender-were presented as absolute and relative frequency. The primary outcome variable was the SCOFF score, with a score $\geq 3$ indicating a risk condition for EDs. Chi-square tests $\left(\chi^{2}\right)$ were used to assess the distribution of SCOFF scores above and under the cut-off of 3 within different BMI categories. For each gender, chi-square $\left(\chi^{2}\right)$ tests evaluated differences between participants with or without a SCOFF score $\geq 3$ regarding self-reported items, and a multivariable logistic regression was performed to outline factors predicting risk for EDs (SCOFF score $\geq 3$ ), expressed as adjusted odds ratios (AORs) with $95 \%$ confidence intervals (CIs). The null hypothesis was rejected for alpha $<0.05$. Analyses were performed using Stata 14 [33].

\section{Results}

A total of 273 subjects did not fill the SCOFF screening scale, and they were, therefore, excluded from analyses. The final sample included 6551 individuals: 3540 boys (54.0\%), and 3011 girls (46.0\%).

Individuals with a SCOFF score $\geq 3$ were $31.0 \%$ of the total sample ( $n=2030): 19.4 \%$ of the boys $(n=687)$, and $44.6 \%$ of the girls $(n=1343)$. A SCOFF score of 5 was observed in $2.4 \%$ of the total sample $(n=154)$, in $1.2 \%$ of the boys $(n=41)$, and in $3.8 \%$ of the girls ( $n: 113)$. In the total sample, the relationship between BMI categories and

Table 1 Percentage of individuals under and above the SCOFF cutoff score for each body mass index category (total sample)

\begin{tabular}{lll}
\hline BMI category & SCOFF $<3$ & SCOFF $\geq 3$ \\
\hline Underweight $(n=175)$ & $134(76.6 \%)$ & $41(23.4 \%)$ \\
Normal weight $(n=5180)$ & $3635(70.2 \%)$ & $1545(29.8 \%)$ \\
Overweight $(n=836)$ & $537(64.2 \%)$ & $299(35.8 \%)$ \\
Obesity $(n=153)$ & $82(53.6 \%)$ & $71(46.4 \%)$ \\
Not available $(n=207)$ & $133(64.3 \%)$ & $74(35.7 \%)$ \\
Total $(N=6551)$ & $4521(69.0 \%)$ & $2030(31.0 \%)$
\end{tabular}

$B M I$ body mass index
SCOFF scores showed an increased prevalence of SCOFF scores $\geq 3$ for higher BMI categories $\left(\chi^{2}=33.90, p<0.001\right.$; Table 1). Similar trends were detected for the subgroups of boys $\left(\chi^{2}=80.37, p<0.001\right.$; Table 2$)$ and girls $\left(\chi^{2}=18.30\right.$, $p<0.001$; Table 3).

In the total sample, 175 subjects had a condition of underweight (2.7\%), 5,180 subjects had a normal weight (79.1\%), 836 subjects were overweight (12.8\%), and $152(2.3 \%)$ had a condition of obesity. BMI was not available for 207 subjects (3.2\%). The gender-specific distribution of BMI categories is shown in Tables 2, 3 .

The gender-specific relationship between SCOFF scores and self-reported variables is reported in Table 4. In both genders, a different distribution was detected for each of the variables presented, except for parental education level. More in details, individuals with high SCOFF scores reported a lower quality of family relationships, more bullying victimization, a younger age at first sexual intercourse, and they referred to experience higher levels of psychological distress. The self-reported quality of peer relationships

Table 2 Percentage of boys under and above the SCOFF cut-off score for each body mass index category

\begin{tabular}{|c|c|c|c|}
\hline BMI category & $\mathrm{SCOFF}<3$ & $\mathrm{SCOFF} \geq 3$ & $\begin{array}{l}\text { Individuals } \\
\text { within BMI } \\
\text { category }\end{array}$ \\
\hline Underweight $(n=57)$ & $50(87.7 \%)$ & $7(12.3 \%)$ & $1.6 \%$ \\
\hline $\begin{array}{l}\text { Normal weight } \\
\quad(n=2699)\end{array}$ & $2259(83.7 \%)$ & $440(16.3 \%)$ & $76.2 \%$ \\
\hline Overweight $(n=562)$ & $399(71.0 \%)$ & $163(29.0 \%)$ & $15.9 \%$ \\
\hline Obesity $(n=99)$ & $59(59.6 \%)$ & $40(40.4 \%)$ & $2.8 \%$ \\
\hline Not available $(n=123)$ & $86(69.9 \%)$ & $37(30.1 \%)$ & $3.5 \%$ \\
\hline Total $(N=3540)$ & $2,853(80.6 \%)$ & $687(19.4 \%)$ & $100 \%$ \\
\hline
\end{tabular}

$B M I$ body mass index

Table 3 Percentage of girls under and above the SCOFF cut-off score for each body mass index category

\begin{tabular}{llll}
\hline & SCOFF $<3$ & SCOFF $\geq 3$ & $\begin{array}{l}\text { Individuals } \\
\text { within BMI } \\
\text { category }\end{array}$ \\
\hline $\begin{array}{l}\text { Underweight } \\
(n=118)\end{array}$ & $84(71.2 \%)$ & $34(28.8 \%)$ & $3.9 \%$ \\
$\begin{array}{l}\text { Normal weight } \\
(n=2481)\end{array}$ & $1376(55.5 \%)$ & $1105(44.5 \%)$ & $82.4 \%$ \\
$\begin{array}{l}\text { Overweight }(n=274) \\
\text { Obesity }(n=54)\end{array}$ & $138(50.4 \%)$ & $136(49.6 \%)$ & $9.1 \%$ \\
$\begin{array}{l}\text { Not available }(n=84) \\
\text { Total }\end{array}$ & $47(56.0 \%)$ & $31(57.4 \%)$ & $1.8 \%$ \\
$(N=3011)$ & $1668(55.4 \%)$ & $1343(44.6 \%)$ & $2.8 \%$ \\
\hline
\end{tabular}

$B M I$ body mass index 
Table 4 Characterization of relational and behavioral variables in individuals with and without a SCOFF score $\geq 3$, divided by gender

\begin{tabular}{|c|c|c|c|c|c|c|c|c|}
\hline & \multicolumn{4}{|l|}{ Boys } & \multicolumn{4}{|l|}{ Girls } \\
\hline & $\mathrm{SCOFF}<3$ & $\mathrm{SCOFF} \geq 3$ & $\chi^{2}$ & $\begin{array}{l}\text { AOR for } \mathrm{SCOFF} \geq 3 \\
\text { and } 95 \% \mathrm{CI} \\
(n=3169)\end{array}$ & $\mathrm{SCOFF}<3$ & $\mathrm{SCOFF} \geq 3$ & $\chi^{2}$ & $\begin{array}{l}\text { AOR for } \mathrm{SCOFF} \geq 3 \\
\text { and } 95 \% \mathrm{CI} \\
(n=2775)\end{array}$ \\
\hline \multicolumn{9}{|c|}{ At least one graduated parent } \\
\hline No & $1813(80.6 \%)$ & $437(19.4 \%)$ & 0.01 & 1 & $1045(54.4 \%)$ & $875(45.6 \%)$ & 0.60 & 1 \\
\hline Yes & $821(80.6 \%)$ & $197(19.4 \%)$ & & $0.98(0.81-1.20)$ & $515(56.0 \%)$ & $405(44.0 \%)$ & & $0.97(0.82-1.15)$ \\
\hline \multicolumn{9}{|c|}{ Quality of family relationships } \\
\hline Good & $2512(81.7 \%)$ & $564(18.3 \%)$ & $68.03 * * *$ & 1 & $1420(58.4 \%)$ & $1013(41.6 \%)$ & $81.14 * * *$ & 1 \\
\hline Intermediate & $248(76.5 \%)$ & $76(23.5 \%)$ & & $0.93(0.68-1.27)$ & $171(43.6 \%)$ & $221(56.4 \%)$ & & $1.34(1.06-1.70)^{*}$ \\
\hline Bad & $65(60.7 \%)$ & $42(39.3 \%)$ & & $1.90(1.20-3.00)^{*}$ & $67(39.6 \%)$ & $102(60.4 \%)$ & & $1.41(1.00-2.01)^{*}$ \\
\hline \multicolumn{9}{|c|}{ Quality of peer relationships } \\
\hline Good & $2581(81.2 \%)$ & $596(18.8 \%)$ & $32.54 * *$ & 1 & $1451(56.4 \%)$ & $1121(43.6 \%)$ & $47.63 * *$ & 1 \\
\hline Intermediate & $211(73.5 \%)$ & $76(26.5 \%)$ & & $1.20(0.87-1.64)$ & $161(46.8 \%)$ & $183(53.2 \%)$ & & $1.08(0.84-1.39)$ \\
\hline $\mathrm{Bad}$ & $35(74.5 \%)$ & $12(25.5 \%)$ & & $0.69(0.33-1.49)$ & $40(53.3 \%)$ & $35(46.7 \%)$ & & $0.57(0.35-0.95)^{*}$ \\
\hline \multicolumn{9}{|c|}{ Bullied in the previous year } \\
\hline No & $1897(84.6 \%)$ & $345(15.4 \%)$ & $11.12 * * *$ & 1 & $1062(62.0 \%)$ & $650(38.0 \%)$ & $11.45 * * *$ & 1 \\
\hline Yes & $892(73.0 \%)$ & $330(27.0 \%)$ & & $1.75(1.45-2.11)^{*}$ & $567(45.4 \%)$ & $683(54.6 \%)$ & & $1.67(1.42-1.96)^{*}$ \\
\hline \multicolumn{9}{|c|}{ Sexual debut before 14 years } \\
\hline No & $2790(81.2 \%)$ & $645(18.8 \%)$ & $29.34 * * *$ & 1 & $1641(55.9 \%)$ & $1295(44.1 \%)$ & $11.71^{*}$ & 1 \\
\hline Yes & $63(60.0 \%)$ & $42(40.0 \%)$ & & $2.28(1.47-3.54)^{*}$ & $27(36.0 \%)$ & $48(64.0 \%)$ & & $1.88(1.11-3.16)^{*}$ \\
\hline \multicolumn{9}{|l|}{ Distress } \\
\hline Low & $2574(82.8 \%)$ & $536(17.2 \%)$ & $77.23 * * *$ & 1 & $12.9 \%)$ & $760(37.1 \%)$ & $143.69 * * *$ & 1 \\
\hline High & $279(64.9 \%)$ & $151(35.1 \%)$ & & $2.17(1.69-2.79)^{*}$ & $382(39.6 \%)$ & $583(60.4 \%)$ & & $2.21(1.86-2.64)^{*}$ \\
\hline
\end{tabular}

Adjusted odds ratios for having a SCOFF score $\geq 3$ are presented (multivariable model)

$A O R$ adjusted odds ratio, $C I$ confidence interval $* p<0.05, * * p<0.01, * * * \mathrm{p}<0.001$. Percentages refer to the single answer for each gender (total number varies due to missing data)

Bold is used to highlight statistically significant results

showed an asymmetrical distribution, with a lower prevalence of high SCOFF scores among those individuals reporting good peer involvement (Table 4).

In both subgroups, AORs for having a SCOFF $\geq 3$ outlined a significant association with bad family relationships, being bullied, being younger than 14 years at first sexual intercourse, and experiencing high distress (Table 4). Gender-specific patterns were observed for girls with an intermediate quality of family relationships (a risk factor not observed for boys), and for girls reporting bad peer relationships - a factor which seemed to exert a protective role (Table 4).

\section{Discussion}

The aim of the present study was to evaluate the prevalence of individuals at risk for EDs using the SCOFF screening questionnaire in a large, representative population of subjects aged 14-19. In addition, the study described this group in terms of associated interpersonal and psychological factors. In the analyzed sample, $19.4 \%$ of the boys and $44.6 \%$ of the girls had a SCOFF score above the cut-off, with greater percentages among higher BMI categories. Factors associated with this condition were experiencing bad family relationships, being teased by peers, having had the first sexual intercourse before the age of 14 , and reporting high levels of perceived distress. Among young women, worse peer relationships were associated with a lower SCOFF score.

To the best of our knowledge, this was the first large epidemiological study to evaluate the prevalence of EDs symptoms in a representative sample of adolescents in Italy. These data confirmed that a remarkable percentage of individuals in this age range present significant body image and weight concerns, as seen in similar studies which, however, outlined a lower proportion of at-risk individuals [34-36]. It is possible to hypothesize that this alarming prevalence may be due to an improved awareness in the general population and to a reduced stigma in reporting ED symptoms, but it may also express a real increase in the occurrence of clinical and subthreshold ED symptoms [1, 8]. From this perspective, the rising incidence of EDs in adults may represent the tip of an 
iceberg with a greater number of vulnerable adolescents who are not detected - and, therefore, potentially not treated. It is noteworthy that-even though the present study confirmed a greater prevalence of ED symptoms among women-a remarkable percentage of boys expressed food- and bodycentered concerns. This result is of particular interest and it cannot be neglected, given the fact that established genderspecific patterns, such as muscularity-oriented disordered eating [37], are not directly addressed by the SCOFF questionnaire. Moreover, this finding indirectly contributes to confirm that the gender gap in ED symptoms may be less pronounced in the general population as compared to clinical samples [38].

In both genders, SCOFF scores increased with BMI: this positive association can be interpreted considering that a large proportion of EDs may rise from overweight conditions and consequent diet attempts [9-11]. In fact, body dissatisfaction, weight concerns, and dietary restraints are clearly associated with weight status [39], potentially resulting in both restrictive [11] and binge-purge disordered eating [40]. In this sense, it is noteworthy that a higher BMI may be associated with worse ED-specific and general psychopathology in adolescents with AN, outlining the need for a close monitoring of atypical AN [41]. For this reason, the use of the questionnaire in this age group may be valuable for the early detection of ED symptomatology across the weight spectrum, i.e. irrespective of an established underweight condition due to dieting or strenuous physical activity.

In the present study, a higher parental education level was not associated with a condition of risk for EDs, a result which is not in line with a previous work on clinically established EDs [14]. In this sense, the cross-sectional design on a general population of adolescents may be inadequate to describe a complex and dynamic phenomenon which involves an expansion of education level in European countries and consequently reduced weight disparities [42] - obesity and overweight conditions being less represented among individuals with higher parental education [43]. For these reasons, extreme caution should be applied to the interpretation of this finding.

Moving forward in the characterization of high-risk conditions for EDs, it has been reported that adolescents often do not have a defined image or structured "behavior model", and their cognitions and activities are, therefore, influenced by a larger number of environmental factors, as compared to adults [44]. Indeed, the present study confirmed that a perceived low quality of family relationships may be associated with altered eating and body weight attitudes [15-17]. Conversely, despite a different distribution among groups, worse peer relationships did not qualify as a risk factor for high SCOFF scores in the multivariable model, and bad relationships even proved to be protective for girls. The present finding is in contrast with a large body of evidence associating interpersonal difficulties-including peer relationshipswith the onset [22] and the worsening [45] of ED symptoms. On the one hand, the self-reported categorical assessment of these dimensions does not allow a detailed comprehension of phenomena underlying the present findings. On the other hand, however, the data observed may be explained by the fact that this parameter can be strongly influenced by active choices of peer involvement (e.g., selection or avoidance), and it may, therefore, underlie coping strategies that cannot be applied in the domestic environment. The same holds true for victims of abusive behaviors from peers: indeed, bullying victimization was significantly associated with high SCOFF scores, confirming that weight and body image concerns cluster with this widespread dysfunctional interaction [20, 21]. Furthermore, the outlined association between EDs risk and a lower age at first sexual intercourse can be explained in the light of the interplay between early puberty and sexual risk-taking [23], which have been implicated in the onset of EDs psychopathology, often on the background of childhood traumatic experiences [24].

To conclude, ED symptomatology proved to be associated with high levels of psychological distress, as outlined through different study designs $[2,19,46]$. With this regard, the non-specific symptoms of anxiety and depression described by the K6 scale may indicate an underlying perceived distress: although at a speculative level, it is possible to hypothesize that these concerns may precede the development of more specific ED symptoms, such as overpreoccupation with body image and eating behavior, which are clearly represented among overweight adolescents who undergo dieting attempts [39]. In this sense, it is noteworthy that dietary restraint tied to high levels of psychological distress expresses a condition of risk for developing an ED [47], confirming the opportunity of a clinical evaluation for a part of subjects who undergo some form of dieting, and that preadolescent overweight and anxious distress recently proved to be associated with the development of ED symptoms in adolescence and young adulthood [48].

\section{Strength and limits}

For the first time, the present study aimed to evaluate the prevalence of EDs symptoms in a large and representative sample of adolescents from the Italian general population, thus contributing to characterize these conditions which are increasingly emerging as a public health concern. In a constantly evolving epidemiological scenario, the study underlined that an alarming percentage of boys and girls expressed some body image concerns, even more than in other European studies [29, 30].

The present findings should be considered according to some limitations. First, the self-report of outcome measures may be associated with under-reporting due to perceived 
stigma tied to specific environmental factors (i.e. family and peer-relationships), pathological weight [49], or denial aimed at avoiding professional help for ED symptomatology. In this sense, the fact that some participants did not fill the SCOFF questionnaire may be an expression of selective non-response, even if no difference in this subsample was observed regarding randomization criteria. Second, the Italian version of the SCOFF questionnaire has low specificity $(87.5 \%)$, and it may overestimate the number of individuals who deserve a clinical evaluation [30]. Third, the crosssectional and observational study design does not allow to draw conclusions on the causative effect of the variables presented. To conclude, the broad categories used for the assessed variables may have produced a reduced variance, and a relative approximation of the investigated phenomena, as discussed for the evaluation of peer relationships. For this reason, multivariable analyses should be interpreted with caution.

\section{Conclusions}

The present study detected a high prevalence of self-reported ED symptomatology among adolescents. This remarkable risk condition proved to be associated with an underlying pattern of perceived problematic family environment, bullying victimization, and higher levels of psychological distress. The identification of these factors may prove useful to ameliorate screening programs for the early detection of EDs, corroborating the need for a further clinical evaluation.

\section{What is already known on this subject?}

An increased incidence of EDs has been observed in the adolescent population during the last decades. In the past years, only a few studies used a validated screening questionnaire to produce an estimate of the prevalence of at-risk subjects in European countries, including Italy.

\section{What this study adds?}

This was the largest epidemiological study which provided the prevalence of subjects at risk for EDs in a representative population of adolescents of Italy. The study detected a remarkable and unexpectedly high prevalence of symptoms in both genders, and it provided a further characterization of putative risk factors among adolescents-thus underlining the need for a thorough screening activity and for future epidemiological monitoring.

Acknowledgements Authors express their appreciation to the Regional Board of Studies (Ufficio Scolastico Regionale Toscana) for their effort in supporting the organization of the present work, and in data collection.
Funding Open access funding provided by Università degli Studi di Firenze within the CRUI-CARE Agreement. The present study was funded by Agenzia Regionale di Sanità (ARS) Toscana through its ordinary budget from Tuscany Regional Administration. ARS contributed to study design, collection, analysis, and interpretation of data.

Availability of data and material The data underlying this article will be shared on reasonable request to the corresponding author.

Code availability The code underlying this article will be shared at reasonable request to the corresponding author.

\section{Declarations}

Conflicts of interests The authors declare that they have no known competing financial interests or personal relationships (other than those affiliations listed on the title page of the manuscript) that could have appeared to influence the work reported in this paper. No grants, honoraria, or other forms of payment were tributed to Authors who contributed to draft and revise the present manuscript.

Ethics approval The study protocol was approved by the Ethics Committee of the sponsoring institution, and it was performed in accordance with the ethical standards contained in the 1964 Declaration of Helsinki and its later amendments.

Consent to participate and consent to publish Written informed consent was collected from participants, and from their parents or legal guardians (for individuals younger than 18 years old). This included the consent to data publication in aggregate form.

Open Access This article is licensed under a Creative Commons Attribution 4.0 International License, which permits use, sharing, adaptation, distribution and reproduction in any medium or format, as long as you give appropriate credit to the original author(s) and the source, provide a link to the Creative Commons licence, and indicate if changes were made. The images or other third party material in this article are included in the article's Creative Commons licence, unless indicated otherwise in a credit line to the material. If material is not included in the article's Creative Commons licence and your intended use is not permitted by statutory regulation or exceeds the permitted use, you will need to obtain permission directly from the copyright holder. To view a copy of this licence, visit http://creativecommons.org/licenses/by/4.0/.

\section{References}

1. Herpertz-Dahlmann B (2015) Adolescent eating disorders: update on definitions, symptomatology, epidemiology, and comorbidity. Child Adolesc Psychiatr Clin N Am 24:177-196. https://doi.org/ 10.1016/j.chc.2014.08.003

2. Swanson SA, Crow SJ, Le Grange D et al (2011) Prevalence and correlates of eating disorders in adolescents. Results from the national comorbidity survey replication adolescent supplement. Arch Gen Psychiatry 68:714-723. https://doi.org/10.1001/archg enpsychiatry.2011.22

3. Santonastaso P, Zanetti T, Sala A et al (1996) Prevalence of eating disorders in italy: a survey on a sample of 16-year-old female students. Psychother Psychosom 65:158-162. https://doi.org/10. $1159 / 000289069$ 
4. Cotrufo P, Barretta V, Monteleone P, Maj M (1998) Full-syndrome, partial-syndrome and subclinical eating disorders: an epidemiological study of female students in Southern Italy. Acta Psychiatr Scand 98:112-115. https://doi.org/10.1111/j.1600-0447. 1998.tb10051.x

5. Miotto P, De Coppi M, Frezza M, Preti A (2003) The spectrum of eating disorders: prevalence in an area of Northeast Italy. Psychiatry Res 119:145-154. https://doi.org/10.1016/S0165-1781(03) 00128-8

6. Abbate-Daga G, Gramaglia C, Malfi G et al (2007) Eating problems and personality traits. An Italian pilot study among 992 high school students. Eur Eat Disord Rev 15:471-478. https://doi.org/ 10.1002/erv.770

7. Patton GC, Selzer R, Coffey C et al (1999) Onset of adolescent eating disorders: population-based cohort study over 3 years. BMJ 318:765-768. https://doi.org/10.1136/bmj.318.7186.765

8. Hudson JI, Hiripi E, Pope HG Jr, Kessler RC (2007) The prevalence and correlates of eating disorders in the National Comorbidity Survey replication. Biol Psychiatry 61:348-358. https://doi. org/10.1016/j.biopsych.2006.03.040

9. Neumark-Sztainer DR, Wall MM, Haines JI et al (2007) Shared risk and protective factors for overweight and disordered eating in adolescents. Am J Prev Med 33:359-369. https://doi.org/10. 1016/j.amepre.2007.07.031

10. Burrows A, Cooper M (2002) Possible risk factors in the development of eating disorders in overweight pre-adolescent girls. Int $\mathrm{J}$ Obes 26:1268-1273. https://doi.org/10.1038/sj.ijo.0802033

11. Lebow J, Sim LA, Kransdorf LN (2015) Prevalence of a history of overweight and obesity in adolescents with restrictive eating disorders. J Adolesc Heal 56:19-24. https://doi.org/10.1016/j. jadohealth.2014.06.005

12. Radwan H, Hasan HA, Najm L et al (2018) Eating disorders and body image concerns as influenced by family and media among university students in Sharjah, UAE. Asia Pac J Clin Nutr 27:695700. https://doi.org/10.6133/apjen.062017.10

13. Pike KM, Hoek HW, Dunne PE (2014) Cultural trends and eating disorders. Curr Opin Psychiatry 27:436-442. https://doi.org/10. 1097/YCO.0000000000000100

14. Goodman A, Heshmati A, Koupil I (2014) Family history of education predicts eating disorders across multiple generations among 2 million Swedish males and females. PLoS ONE 9:e106475. https://doi.org/10.1371/journal.pone.0106475

15. Wertheim EH, Paxton SJ, Maude D et al (1992) Psychosocial predictors of weight loss behaviors and binge eating in adolescent girls and boys. Int J Eat Disord 12:151-160. https://doi.org/10. 1002/1098-108X(199209)12:2\%3c151::AID-EAT2260120205\% 3e3.0.CO;2-G

16. Cromley T, Neumark-Sztainer D, Story M, Boutelle KN (2010) Parent and family associations with weight-related behaviors and cognitions among overweight adolescents. J Adolesc Heal 47:263-269. https://doi.org/10.1016/j.jadohealth.2010.02.009

17. Rodgers RF, Simone M, Franko DL et al (2021) The longitudinal relationship between family and peer teasing in young adulthood and later unhealthy weight control behaviors: The mediating role of body image. Int J Eat Disord. https://doi.org/10.1002/eat.23492

18. Gander M, Sevecke K, Buchheim A (2015) Eating disorders in adolescence: attachment issues from a developmental perspective. Front Psychol 6:1136. https://doi.org/10.3389/fpsyg.2015.01136

19. Ahorsu DK, Lin C-Y, Imani V et al (2020) A prospective study on the link between weight-related self-stigma and binge eating: Role of food addiction and psychological distress. Int J Eat Disord 53:442-450. https://doi.org/10.1002/eat.23219

20. Ali MM, Amialchuk A, Heiland FW (2011) Weight-related behavior among adolescents: the role of peer effects. PLoS ONE 6:e21179. https://doi.org/10.1371/journal.pone.0021179
21. Lian Q, Su Q, Li R et al (2018) The association between chronic bullying victimization with weight status and body self-image: a cross-national study in 39 countries. PeerJ 6:e4330. https://doi. org/10.7717/peerj.4330

22. Cardi V, Tchanturia K, Treasure J (2018) Premorbid and illnessrelated social difficulties in eating disorders: an overview of the literature and treatment developments. Curr Neuropharmacol 16:1122-1130. https://doi.org/10.2174/1570159X166661801181 00028

23. Mangweth-Matzek B, Rupp CI, Hausmann A et al (2007) Menarche, puberty, and first sexual activities in eating-disordered patients as compared with a psychiatric and a nonpsychiatric control group. Int J Eat Disord 40:705-710. https://doi.org/10.1002/ eat.20431

24. Castellini G, D’Anna G, Rossi E et al (2020) Dysregulated sexuality in women with eating disorders: the role of childhood traumatic experiences. J Sex Marital Ther. https://doi.org/10.1080/ 0092623X.2020.1822484

25. Kaltiala-Heino R, Rimpel M, Rissanen A, Rantanen P (2001) Early puberty and early sexual activity are associated with bulimic-type eating pathology in middle adolescence. J Adolesc Heal 28:346-352. https://doi.org/10.1016/S1054-139X(01) 00195-1

26. Monteleone AM, Ruzzi V, Patriciello G et al (2020) Emotional reactivity and eating disorder related attitudes in response to the trier social stress test: An experimental study in people with anorexia nervosa and with bulimia nervosa. J Affect Disord 274:2330. https://doi.org/10.1016/j.jad.2020.05.051

27. Cole TJ, Bellizzi MC, Flegal KM, Dietz WH (2000) Establishing a standard definition for child overweight and obesity worldwide: international survey. BMJ 320:1240. https://doi.org/10.1136/bmj. 320.7244 .1240

28. Cole TJ, Flegal KM, Nicholls D, Jackson AA (2007) Body mass index cut offs to define thinness in children and adolescents: international survey. BMJ 335:194. https://doi.org/10.1136/bmj.39238. 399444.55

29. Morgan JF, Reid F, Lacey JH (1999) The SCOFF questionnaire: assessment of a new screening tool for eating disorders. BMJ 319:1467-1468. https://doi.org/10.1136/bmj.319.7223.1467

30. Di Fiorino M, Pannocchia L, Giannini M (2007) Contributo alla validazione della versione italiana dello SCOFF: studio su una popolazione psichiatrica. Psichiatr e Territ XXIV:1-2

31. Kessler RC, Green JG, Gruber MJ et al (2010) Screening for serious mental illness in the general population with the K6 screening scale: results from the WHO World Mental Health (WMH) survey initiative. Int J Methods Psychiatr Res 19:4-22. https://doi.org/10. 1002/mpr.310

32. Mewton L, Kessler RC, Slade T et al (2016) The psychometric properties of the kessler psychological distress scale (K6) in a general population sample of adolescents. Psychol Assess 28:1232-1242. https://doi.org/10.1037/pas0000239

33. StataCorp, (2015) Stata Statistical Software: Release 14. StataCorp LP, College Station (Texas)

34. Hautala LA, Junnila J, Helenius H et al (2008) Towards understanding gender differences in disordered eating among adolescents. J Clin Nurs 17:1803-1813. https://doi.org/10.1111/j.13652702.2007.02143.x

35. Hölling H, Schlack R (2007) Eating disorders in children and adolescents. First results of the German Health Interview and Examination Survey for Children and Adolescents (KiGGS). Bundesgesundheitsblatt Gesundheitsforschung Gesundheitsschutz 50:794-799. https://doi.org/10.1007/s00103-007-0242-6

36. Lichtenstein MB, Hemmingsen SD, Støving RK (2017) Identification of eating disorder symptoms in Danish adolescents with the 
SCOFF questionnaire. Nord J Psychiatry 71:340-347. https://doi. org/10.1080/08039488.2017.1300322

37. Nagata JM, Ganson KT, Murray SB (2020) Eating disorders in adolescent boys and young men: an update. Curr Opin Pediatr 32:476-481. https://doi.org/10.1097/MOP.0000000000000911

38. Sweeting H, Walker L, MacLean A et al (2015) Prevalence of eating disorders in males: a review of rates reported in academic research and UK mass media. Int J Mens Health. https://doi.org/ 10.3149/jmh. 1402.86

39. Goldfield GS, Moore C, Henderson K et al (2010) Body dissatisfaction, dietary restraint, depression, and weight status in adolescents. J Sch Health 80:186-192. https://doi.org/10.1111/j. 1746-1561.2009.00485.x

40. Gonçalves S, Machado BC, Martins C et al (2016) Retrospective correlates for bulimia nervosa: a matched case-control study. Eur Eat Disord Rev 24:197-205. https://doi.org/10.1002/erv.2434

41. Monteleone AM, Mereu A, Cascino G et al (2021) The validity of the fifth and the 10th Body Mass Index percentile as weight cut-offs for anorexia nervosa in adolescence: No evidence from quantitative and network investigation of psychopathology. Eur Eat Disord Rev 29:232-244. https://doi.org/10.1002/erv.2814

42. Etile F (2014) Education policies and health inequalities: Evidence from changes in the distribution of body mass index in France, 1981-2003. Econ Hum Biol 13:46-65. https://doi.org/ 10.1016/j.ehb.2013.01.002

43. Apouey BH, Geoffard P-Y (2016) Parents' education and child body weight in France: The trajectory of the gradient in the early years. Econ Hum Biol 20:70-89. https://doi.org/10.1016/j.ehb. 2015.10.005

44. Vega Alonso AT, Rasillo Rodríguez MA, Lozano Alonso JE et al (2005) Eating disorders. Prevalence and risk profile among secondary school students. Soc Psychiatry Psychiatr Epidemiol 40:980-987. https://doi.org/10.1007/s00127-005-0996-9

45. Monteleone AM, Cascino G, Marciello F et al (2021) Risk and resilience factors for specific and general psychopathology worsening in people with Eating Disorders during COVID-19 pandemic: a retrospective Italian multicentre study. Eat Weight Disord. https://doi.org/10.1007/s40519-020-01097-x

46. Lee KS, Vaillancourt T (2018) Longitudinal associations among bullying by peers, disordered eating behavior, and symptoms of depression during adolescence. JAMA Psychiat 75:605-612. https://doi.org/10.1001/jamapsychiatry.2018.0284

47. Isomaa R, Isomaa A-L, Marttunen $M$ et al (2010) Psychological distress and risk for eating disorders in subgroups of dieters. Eur Eat Disord Rev 18:296-303. https://doi.org/10.1002/erv.1004

48. van Eeden AE, Oldehinkel AJ, van Hoeken D, Hoek HW (2021) Risk factors in preadolescent boys and girls for the development of eating pathology in young adulthood. Int J Eat Disord. https:// doi.org/10.1002/eat.23496

49. Chau N, Chau K, Mayet A et al (2013) Self-reporting and measurement of body mass index in adolescents: refusals and validity, and the possible role of socioeconomic and health-related factors. BMC Public Health 13:815. https://doi.org/10.1186/ 1471-2458-13-815

Publisher's Note Springer Nature remains neutral with regard to jurisdictional claims in published maps and institutional affiliations. 